\title{
PREPARAÇÃO E UTILIZAÇÃO DE UMA ARGILA ESMECTÍTICA ORGANOFÍLICA COMO ADSORVENTE DE FENOL
}

Jorge Vinícius Fernandes Lima Cavalcanti, César Augusto Moraes de Abreu e Maurício Alves da Motta Sobrinho*

Departamento de Engenharia Química, Universidade Federal de Pernambuco, Av. Prof. Artur de Sá, s/n, Cidade Universitária, 50740-521 Recife - PE, Brasil

Osmar Souto Baraúna e Lívia Aristela Pereira Portela

Laboratório de Materiais, Instituto de Tecnologia de Pernambuco, Av. Prof. Luiz Freire, 700, Cidade Universitária, 50740-540

Recife - PE, Brasil

Recebido em 28/8/08; aceito em 13/4/09; publicado na web em 31/8/09

PREPARATION AND USE OF A ORGANOPHILIC SMECTITIC CLAY FOR ADSORPTION OF PHENOL. The main goal of this research was the preparation and use of a organophilic smectitic clay able to promoting the adsorption of phenol. In this work was used a natural clay called Chocolate, from Campina Grande - PB (Brazil). The natural clay was treated with a solution of sodium carbonate. After this the sodium clay was treated with quaternary ammonium salt. The adsorptive study was conducted by different values of $\mathrm{pH}$ and temperature. The results showed a better performance in adsorptive at $\mathrm{pH} 7$ and temperature $30{ }^{\circ} \mathrm{C}$, with removal of more than $80 \%$ of phenol.

Keywords: organophilic clay; adsorption; phenol.

\section{INTRODUÇÃO}

O uso crescente de compostos e produtos originados do petróleo tem acarretado em problemas sérios à saúde humana e ao meio ambiente. A argila hidrofílica montmorilonita é um adsorvente ineficaz para compostos orgânicos aromáticos que se movem frequentemente dos locais contaminados. Entretanto, pode-se realçar a eficiência adsortiva desta argila pela substituição dos cátions inorgânicos presentes em sua estrutura original pelos surfactantes catiônicos maiores, como os cátions amônio quaternários, criando adsorventes que retardam a migração de tais poluentes. ${ }^{1}$

A definição clássica designa argila como um material natural, terroso, de granulação fina, que quando umedecido com água apresenta plasticidade. ${ }^{2,3}$ Os minerais constituintes das argilas são os argilominerais, sendo os mesmos silicatos hidratados que possuem estrutura em camadas constituídas por folhas contínuas formadas por tetraedros de silício (ou alumínio) e oxigênio, e folhas formadas por octaedros de alumínio (magnésio ou ferro), oxigênio e hidroxilas. A nomenclatura para os tipos de camadas é uma simples expressão da razão entre as folhas tetraédricas e as folhas octaédricas. Assim sendo, um argilomineral com camada 1:1 tem uma folha tetraédrica e uma folha octaédrica, enquanto que um argilomineral do tipo 2:1 apresenta duas folhas tetraédricas e uma folha octaédrica interna. A distância interlamelar ou distância interplanar basal também é utilizada para classificar as diferentes argilas existentes., ${ }^{3,4}$

Segundo pesquisa realizada, o tratamento de argilas esmectíticas com sais quaternários de amônio em concentrações superiores a sua capacidade de troca de cátions (CTC) colabora com o aumento da capacidade adsortiva, devido à fixação de íons amônio quaternário nas regiões intercamadas e na superfície externa dos argilominerais. A influência da inclusão do sal quaternário de amônio na argila pode ser explicada pela substituição dos cátions sódio pelos cátions amônio quaternário, passando-a de hidrofílica a organofílica. A parte catiônica das moléculas do sal quaternário de amônio ocupa os sítios onde anteriormente estavam os cátions sódio e as longas cadeias orgânicas situam-se entre as camadas do argilomineral. A efetiva

*e-mail: mottas@ufpe.br intercalação dos sais quaternários de amônio entre as camadas dos argilominerais pode ser acompanhada por difração de raios-X dos materiais organofílicos, observando-se o aumento da distância interplanar basal $\mathrm{d}_{001}$, que passa de valores geralmente situados entre 1,2 e 1,6 nm (dependendo da umidade da amostra) para valores situados geralmente entre 2,0 e $4,0 \mathrm{~nm} .^{5}$

Um trabalho de pesquisa desenvolveu um esquema para obtenção da argila organofílica após tratamento com sódio e sal quaternário de amônio. Os autores basearam-se na substituição dos cátions inorgânicos pelo cátion sódio e, em seguida, pelo cátion amônio quaternário nas regiões intercamadas. ${ }^{6}$

Ao se entender o desenvolvimento compatível com a preservação dos recursos naturais, novas técnicas de tratamento de efluentes se fazem necessárias, a fim de que seja possível aliar baixos custos à eficiência da preservação ambiental e da saúde pública. As argilas apresentam alta viabilidade técnico-econômica decorrente do seu potencial de adsorção, que associado à sua disponibilidade abundante as tornam adsorventes de baixo custo. A argila montmorilonita, do grupo das esmectitas, é em relação ao carvão ativado bem mais acessível. ${ }^{7}$

Água misturada com derivados de petróleo é produzida em grandes volumes em muitos processos industriais de produção desses derivados e de refino do óleo. Esta mistura deve ser tratada para separar os derivados de petróleo da água antes que a mesma possa retornar ao meio ambiente ou mesmo ser reutilizada no processo. Geralmente são instalados equipamentos de separação como coalescedores, sedimentadores por gravidade, flotadores com ar dissolvido dentre outros, visando reduzir as concentrações dos derivados de petróleo nos efluentes. Os tratamentos com os processos convencionais quando não são economicamente viáveis não apresentam eficiência adequada de separação ou produzem grandes quantidades de lama que necessitam também de tratamento. ${ }^{8}$

De acordo com uma pesquisa, o fenol aparece nos efluentes de uma refinaria de petróleo oriundo das etapas de craqueamento catalítico, produção de lubrificantes e solventes e nas águas de lavagem da gasolina. A concentração média deste aromático nos efluentes foi $154 \mathrm{mg} \mathrm{L}^{-1} .{ }^{9}$ Em outro trabalho publicado, a faixa de concentração dos efluentes fenólicos de uma refinaria estava entre 0,9 e $60 \mathrm{mg} \mathrm{L}^{-1} .^{10}$ 
No Brasil, o Conselho Nacional de Meio Ambiente (CONAMA), através da Resolução 357/2005, estabelece parâmetros orgânicos e inorgânicos como padrões de lançamento de efluentes de qualquer fonte poluidora. A concentração máxima de fenóis totais, em efluentes, não deve exceder $0,5 \mathrm{mg} \mathrm{L}^{-1} .^{11}$

A presença de grupos hidroxilas confere aos fenóis a capacidade de formar ligações de hidrogênio, o que dá aos mesmos pontos de ebulição acima de compostos orgânicos de massas moleculares próximas. O fenol é um composto sólido de cor branca e aparência cristalina, fórmula molecular $\mathrm{C}_{6} \mathrm{H}_{5} \mathrm{OH}$, massa molar $94,11 \mathrm{~g} \mathrm{~mol}^{-1}$, densidade $1,07 \mathrm{~g} \mathrm{~mL}^{-1}$, ponto de fusão $40,5{ }^{\circ} \mathrm{C}$, ponto de ebulição $181,7{ }^{\circ} \mathrm{C}$ e solubilidade em água a $20^{\circ} \mathrm{C}$ igual a $8,3 \mathrm{~g}$ para $100 \mathrm{~g}$ de água. Apresenta momento dipolar igual a 1,7 D e constante ácida $\left(\mathrm{pk}_{\mathrm{A}}\right)$ 9,95. É uma molécula com diâmetro igual a 0,62 nm, quando considerada esférica. ${ }^{12,13}$

Os resíduos líquidos gerados por refinarias possuem diferentes composições químicas incluindo óleos e graxas, fenóis, BTEX (benzeno, tolueno, etil-benzeno e xilenos), amônia, sólidos suspensos, cianetos, sulfitos, compostos nitrogenados e metais pesados, tais como ferro, níquel, cromo, cobre, molibdênio, selênio, vanádio, zinco e cádmio. Buscando-se avaliar e monitorar o impacto ambiental provocado pelo lançamento de efluentes nos corpos hídricos, testes de toxicidade são muito utilizados como indicadores destes danos causados ao ambiente aquático. Os testes realizados em peixes, invertebrados e algas revelaram que a maioria dos efluentes de refinaria é tóxico, provocando nestes organismos, não apenas efeitos letais, como também alterações quanto ao seu crescimento e reprodução. ${ }^{14}$

Um estudo afirma que dentre os poluentes orgânicos presentes nos efluentes de refinarias de petróleo em concentrações mais elevadas se destaca o fenol, resíduo que é gerado principalmente no craqueamento catalítico e no fracionamento de óleo cru. Além dessas fontes alguns processos utilizam fenol como solvente, contribuindo para o aumento da concentração de resíduos fenólicos nesses efluentes. Nesta pesquisa, foi avaliado o impacto causado pelo lançamento de efluentes de uma refinaria em um corpo hídrico receptor localizado na Nigéria. Este trabalho verificou que a quantidade de fenol no efluente tratado lançado no delta do rio receptor apresentou um teor de $1,84 \mathrm{mg} \mathrm{L}^{-1}$, valor superior ao máximo permitido pela legislação nigeriana que estabelece $0,5 \mathrm{mg} \mathrm{L}^{-1}$. O fenol é um dos resíduos mais difíceis de ser removido, normalmente envolvendo processos com eficiência pouco satisfatória e custos operacionais elevados. Além disso, trata-se de uma substância altamente tóxica, que pode provocar mortandade de peixes e outros organismos aquáticos. ${ }^{15}$

Tendo em vista a possibilidade de uma alternativa de remoção de fenol por adsorção em argila esmectítica organofílica, o presente trabalho teve como principais objetivos a preparação e caracterização deste material e sua utilização como adsorvente, para sistemas em equilíbrio com diferentes valores de $\mathrm{pH}$ e temperatura. A avaliação estatística do modelo matemático adequado ao processo também se fez necessária.

\section{REVISÃO BIBLIOGRÁFICA - UTILIZAÇÃO DE ARGILAS ESMECTÍTICAS ORGANOFÍLICAS COMO ADSORVENTE DE FENOL}

Vários são os trabalhos disponíveis na literatura que tratam da remoção de fenol por adsorção em argilas organofílicas.

Um grupo de pesquisa utilizou um sistema combinado de adsorção e ultrafiltração de argila caulinita e montmorilonita, concluindo que a rejeição à remoção do fenol e do o-cresol estava relacionada com o aumento do pH do sistema. Este mesma influência pôde ser observada em outros trabalhos científicos..$^{16,17}$
Uma pesquisa observou a eficiência de adsorção do fenol utilizando diferentes tratamentos para ativação de uma argila bentonita sódica, tais como surfactante catiônico brometo de cetil-tri-metil-amônio (CTAB), alumínio como pilarizante, CTAB e alumínio combinados (CTAB/Al), ciclo-hexano, bentonita tratada termicamente a 850 ${ }^{\circ} \mathrm{C}$ durante $30 \mathrm{~min}$ (tratamento físico isento de agentes químicos) e bentonita in natura, tendo os resultados apontado para a argila bentonita $\mathrm{CTAB} / \mathrm{Al}$ como a mais eficiente e a in natura como a menos eficiente. Estudou também a influência da temperatura e verificou-se que o aumento da mesma, utilizando 25,35 e $45^{\circ} \mathrm{C}$, desfavorecia a eficiência adsortiva. ${ }^{18}$

Outro trabalho abordou a influência da modificação das argilas bentonitas nas suas propriedades adsortivas, tratando-as com brometo de tetra-decil-tri-metil-amônio (TDTAB) e brometo de hexa-deciltri-metil-amônio (HDTAB), com mudanças em 25, 50 e 100\% da capacidade de troca catiônica desse adsorvente. O tempo de equilíbrio foi de aproximadamente $7 \mathrm{~h}$ e resultados cinéticos indicaram a possível presença de regiões heterogêneas nas superfícies das argilas modificadas com 25 e $50 \%$ de sua capacidade de troca catiônica. As argilas modificadas com TDTAB e HDTAB, em 100\% da sua CTC, obtiveram os melhores resultados para as eficiências de remoção. ${ }^{19}$

Avaliando parâmetros termodinâmicos referentes ao estudo da adsorção do p-cloro-fenol na argila montmorilonita TBAM, uma pesquisa concluiu que este material pode ser um bom adsorvente para este composto. ${ }^{20}$

Em artigo publicado, foi observada a adsorção do composto fenol e dos isômeros 2, 3 e 4 cloro-fenol, em argilas esmectíticas tratadas com cloreto de tetra-metil-amônio (TMA) e brometo de tetra-metilfosfônio (TMP). Os experimentos foram realizados com $100 \mathrm{mg}$ de argila em soluções de adsorvato 0,02 a $0,15 \mathrm{mmol} 100 \mathrm{~mL}^{-1}$, em erlenmeyer de $250 \mathrm{~mL}$, a $20^{\circ} \mathrm{C}$. Constatou-se que a argila esmectita tratada com TMP foi melhor adsorvente que a mesma tratada com TMA. $^{21}$

Outro grupo de pesquisa investigou a adsorção e retenção de hidrocarbonetos presentes na gasolina pelas argilas bentonitas organofílicas modificadas por sais quaternários de amônio, tais como benzil-tri-etil-amônio (BTEA) e hexa-decil-tri-metil-amônio (HDTMA). Os resultados do equilíbrio adsortivo para o benzeno seguem o modelo de Langmuir, para o BTEA, com capacidade de troca de cátions de 40 a $120 \%$, apresentando uma redução na eficiência de adsorção mediante o aumento da CTC. Já para o HDTMA os resultados apontaram para uma isoterma numa região linear, com CTC de 25 a $100 \%$. Em ambos os casos os resultados para remoção e retenção de contaminantes foram satisfatórios, concluindo que tais materiais podem ser utilizados para conter vazamentos em tanques contendo hidrocarbonetos. ${ }^{22}$

\section{MODELAGEM MATEMÁTICA}

\section{Equilíbrio adsortivo - isoterma de Langmuir-Freundlich}

O equilíbrio adsortivo representa o estado de igualdade entre a taxa cinética adsortiva e dessortiva. Uma das equações clássicas representantes deste estado é a isoterma de Langmuir-Freundlich, expressa pela Equação 1:

$\theta_{A}=\frac{K_{A} C_{A}{ }^{n}}{1+K_{A} C_{A}{ }^{n}}$

Nesta equação, $K_{A}$ representa a constante de equilíbrio adsortivo $\left(\mathrm{L} \mathrm{mg}^{-1}\right), C_{A}$ a concentração de adsorvato na fase líquida $\left(\mathrm{mg} \mathrm{L}^{-1}\right) \mathrm{e}$ $n$ a intensidade adsortiva. $\mathrm{O}$ valor de $n$ pode ser igual a 1 , descrevendo então a isoterma de Langmuir, que considera adsorção em 
monocamadas, ou pode ser diferente de 1 , considerando adsorção em multicamadas, previsto pela isoterma de Freundlich. Defini-se o parâmetro $\theta_{A}$ como a fração dos sítios ocupados por adsorção do componente "A" em relação ao total de sítios ocupados na saturação, podendo-se representá-lo de acordo com a Equação 2:

$\theta_{A}=\frac{Q_{A}}{Q_{A}{ }^{S A T}}$

sendo $Q_{A}$ a concentração de adsorvato na fase sólida $\left(\mathrm{mg} \mathrm{g}^{-1}\right)$ e $Q_{A}{ }^{S A T}$ um parâmetro constante que representa a concentração máxima de sítios disponíveis do material adsorvente por grama de sólido (grama de adsorvato na saturação por grama de sólido), também denominado de capacidade máxima adsortiva.

Reescrevendo-se a Equação 1, em função da capacidade máxima adsortiva e da concentração do adsorvato na fase sólida, obtém-se a Equação 3:

$\frac{Q_{A}}{Q_{A}{ }^{S A T}}=\frac{K_{A} C_{A}{ }^{n}}{1+K_{A} C_{A}{ }^{n}}$

Reorganizando-se a Equação 3 e ajustando-se um valor para $n$, pode-se obter uma curva linear, conforme expressa a Equação 4:

$\frac{1}{Q_{A}}=\frac{1}{K_{A} Q_{A}^{S A T}}\left(\frac{1}{C_{A}}\right)^{n}+\frac{1}{Q_{A}^{S A T}}$

Os parâmetros $K_{\mathrm{A}}$ e $Q_{\mathrm{A}}^{S A T}$ podem ser determinados pelos coeficientes angular e linear da reta formada. Os valores de $C_{A}$ são determinados experimentalmente, enquanto que os valores de $Q_{A}$ podem ser calculados através do balanço geral representado pela Equação 5:

$Q_{A}=\frac{\left(C_{A 0}-C_{A}\right) V}{m_{s}}$

sendo $C_{A 0}\left(\mathrm{mg} \mathrm{L}^{-1}\right)$ a concentração inicial do adsorvato, $V(\mathrm{~L})$ o volume da solução e $m_{s}(\mathrm{~g})$ a massa do adsorvente.

\section{Análise de variância - ANOVA}

A análise de variância (ANOVA) é o método mais usado para se avaliar numericamente a qualidade do ajuste de um modelo. ${ }^{23}$ Esta análise estatística se baseia na relação existente entre a soma quadrática devido à regressão e a soma quadrática em torno da média, expressa pela Equação 6:

$$
D^{2}=\frac{\sum(\hat{a}-\bar{a})^{2}}{\Sigma(a-\bar{a})^{2}}
$$

sendo $\hat{a}$ os valores calculados pelo o modelo em relação ao ponto em questão, $a$ os valores determinados experimentalmente e $\bar{a}$ a média global. $D^{2}$ é chamado de coeficiente de determinação do modelo. O valor máximo de $D^{2}$ é 1 , e só ocorrerá se não houver resíduo nenhum e, portanto, toda a variação em torno da média for explicada pela regressão. Quanto mais próximo de 1 estiver o valor de $D^{2}$, melhor terá sido o ajuste do modelo às respostas observadas. ${ }^{23}$

\section{PARTE EXPERIMENTAL}

\section{Preparação do material adsorvente}

Buscou-se, pelo tratamento com sal quaternário de amônio (cloreto de tri-metil-hexa-decil-amônio), que a argila esmectítica previamente tratada com sódio, através da troca catiônica pela inserção de carbonato de sódio, em condições otimizadas, desenvolvesse propriedades organofílicas e tixotrópicas equivalentes às exigidas pela Norma N-2258 da PETROBRAS, para argilas utilizadas em fluidos de perfuração de poços de petróleo base óleo, capazes de adsorver fenol e deixar o efluente nas condições estabelecidas pela Resolução 357/2005 do CONAMA.

O tratamento da argila com carbonato de sódio foi realizado com uma proporção de $50 \mathrm{~g}$ de argila Chocolate in natura com $500 \mathrm{~mL}$ de água deionizada e $10 \mathrm{~mL}$ de uma solução $265 \mathrm{~g} \mathrm{~L}^{-1}$ deste sal, agitando a dispersão a $800 \mathrm{rpm}$, durante $3 \mathrm{~h}$, a uma temperatura $45^{\circ} \mathrm{C}$, em um reator de bancada com controle de temperatura e agitação, conforme mostra a Figura 1. A dispersão foi filtrada a vácuo e o sólido foi posto em uma estufa com circulação forçada de ar à $100^{\circ} \mathrm{C}$ durante $24 \mathrm{~h}$. Em seguida, a argila sódica foi destorroada em almofariz e peneirada (\# 0,075 mm).

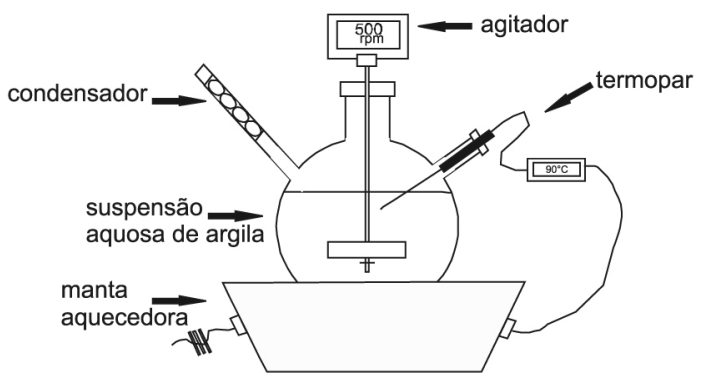

Figura 1. Reator com controle e indicação de temperatura e agitação

O tratamento com sal quaternário de amônio realizou-se com a argila Chocolate sódica em concentrações de sal quaternário de amônio igual a $150 \%$ da sua capacidade de troca de cátions (CTC), no mesmo sistema anterior, com temperatura ambiente $\left(27^{\circ} \mathrm{C}\right)$ e agitação a $800 \mathrm{rpm}$, durante $2 \mathrm{~h}$. Realizou-se a filtração a vácuo e o sólido foi posto na estufa com circulação forçada de ar a $60{ }^{\circ} \mathrm{C}$ durante $72 \mathrm{~h}$. A argila organofílica foi então destorroada e peneirada (\# 0,075 mm).

Para caracterização da argila organofílica, foram realizados quatro ensaios: capacidade de troca de cátions (CTC), realizado no Instituto de Pesquisas Agronômicas (IPA) do Estado de Pernambuco; difratometria de raios-X, realizada em um difratômetro de raios-X marca Rigaku, modelo Ultima; área superficial específica (BET), realizada num analisador de área superficial marca Micromeritics, modelo ASAP 2010; potencial zeta, realizado num medidor de potencial eletroacústico marca MATEC, modelo ESA 9800.

\section{Estudo adsortivo}

$\mathrm{O}$ estudo adsortivo foi realizado com diferentes valores de $\mathrm{pH}$, iguais a 7,0, acidificado com ácido sulfúrico, 8,3 representando o estado natural do $\mathrm{pH}$ do sistema adsortivo e 9,0, alcalinizado com hidróxido de sódio. As temperaturas foram iguais a 30 e $40{ }^{\circ} \mathrm{C}$, em $\mathrm{pH} 8,3$, utilizando-se uma mesa agitadora com controle de temperatura. A massa de argila organofílica foi igual a $2 \mathrm{~g}$ e o volume da solução fenólica igual a $100 \mathrm{~mL}$. Foram preparadas 7 soluções analíticas com concentrações inicias deste aromático entre 20 e $110 \mathrm{mg} \mathrm{L}^{-1}$, suficientemente altas para o efluente de uma refinaria, porém trabalhando-se em condições maximizadas de adversidade e justificando-se o uso dos processos adsortivos, que não se ajustam bem às baixas concentrações. As soluções foram analisadas por cromatografia líquida, com fase móvel formada por $40 \%$ de metanol e $60 \%$ de água, num cromatógrafo líquido de alta performance (HPLC) marca Shimadzu, modelo LC-20A, Prominence, com detector UV 
$(\lambda=270 \mathrm{~nm})$, utilizando-se uma coluna C-18 Shim-Pack $(5 \mu \mathrm{m}$, 150 x 4,6 mm di) CLC-ODS (M). O tempo de contato do sistema argila/fenol, para garantir o estabelecimento do estado de equilíbrio adsortivo, foi igual a $24 \mathrm{~h}$.

\section{RESULTADOS E DISCUSSÃO}

\section{Caracterização do material adsorvente}

Para caracterização do material adsorvente, conforme descrito anteriormente, foram realizados quatro ensaios.

A capacidade de troca de cátions (CTC) foi realizada no Instituto de Pesquisas Agronômicas (IPA) do Estado de Pernambuco e os resultados estão sumarizados na Tabela 1. Para a argila Chocolate in natura, faz-se referência com I, enquanto que para a argila Chocolate sódica, faz-se referência com II.

Tabela 1. CTC da argila Chocolate in natura (I) e sódica (II), em meq $100 \mathrm{~g}^{-1}$ de argila

\begin{tabular}{lcccccccc}
\hline & $\mathrm{Ca}^{2+}$ & $\mathrm{Mg}^{2+}$ & $\mathrm{Na}^{+}$ & $\mathrm{K}^{+}$ & $\mathrm{Al}^{3+}$ & $\mathrm{H}^{+}$ & $\mathrm{CTC}$ & $\mathrm{pH}$ \\
\hline (I) & 17,55 & 36,20 & 13,13 & 0,55 & 0,10 & 3,78 & 71,31 & 5,90 \\
(II) & 1,60 & 2,35 & 74,74 & 0,55 & 0,00 & 0,00 & 79,34 & 10,10 \\
\hline
\end{tabular}

Observou-se que a troca de cálcio e magnésio por sódio, na argila Chocolate, foi extremamente bem sucedida. Isto implica numa troca bem mais efetiva com o sal quaternário de amônio uma vez que a argila tratada com sódio é mais suscetível à hidratação.

A difratometria de raios- $\mathrm{X}$ indicou o aumento da distância interplanar basal da argila esmectítica na sua versão sódica hidratada, bem como das versões organofílicas, antes e após adsorção do fenol, estando estes resultados mostrados nas Figuras 2 e 3.

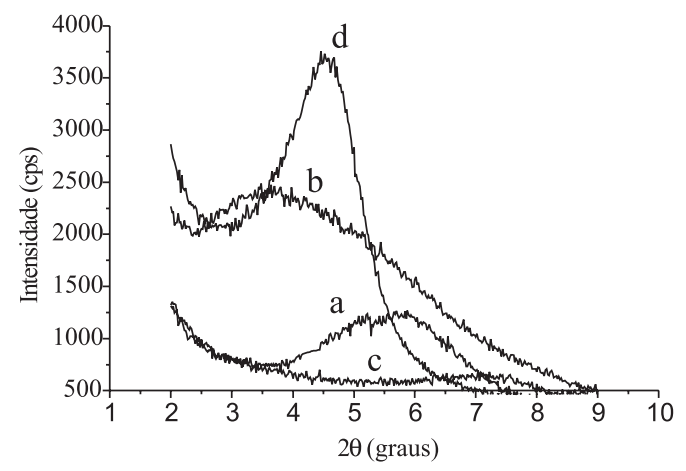

Figura 2. Difração de raios- $X$ das argilas in natura seca (a) e hidratada (b); sódica seca (c) e hidratada (d)

Os espaçamentos basais ( $\mathrm{nm})$, para as argilas in natura seca a $300{ }^{\circ} \mathrm{C}$ e hidratada; sódica seca a $100{ }^{\circ} \mathrm{C}$ e hidratada; organofílica antes e após a adsorção do fenol estão apresentados na Tabela 2.

Os resultados das análises por difração de raios-X mostraram um aumento no espaçamento basal da argila organofílica em relação às argilas in natura e sódica (seca). Também mostraram um leve aumento no pico da argila organofílica após adsorção do fenol quando comparada com a mesma antes da adsorção.

$\mathrm{O}$ fato da difração de raios-X da argila sódica ter revelado um pico de $1,260 \mathrm{~nm}$ está relacionado à sua secagem realizada após tratamento por sódio. Comparando os raios-X das amostras in natura e sódica, ambas sem hidratação, não é possível se fazer uma análise muito precisa sobre o que aconteceu na região intercamadas da argila sódica nas condições em que elas foram analisadas (por DRX). Isto acontece porque a amostra sódica foi submetida a uma secagem à temperatura de $100{ }^{\circ} \mathrm{C}$ por um tempo longo para permitir o peneiramento. Isto provoca uma desidratação da região intercamadas, que é tanto mais severa quanto maior for o tempo de secagem. ${ }^{2}$ A melhor forma de comparar a eficiência da troca catiônica cálcio/sódio corresponde àquela em que se faz um tratamento com água. Neste caso, colocaram-se as duas argilas (in natura e sódica) em condições equivalentes de hidratação e a diferença de comportamento adsortivo entre elas ficou evidente. É o que pôde ser visto por comparação entre os DRX das amostras in natura e sódica hidratadas, verificado na Figura 2, e ratificado pelos resultados da Tabela 2.

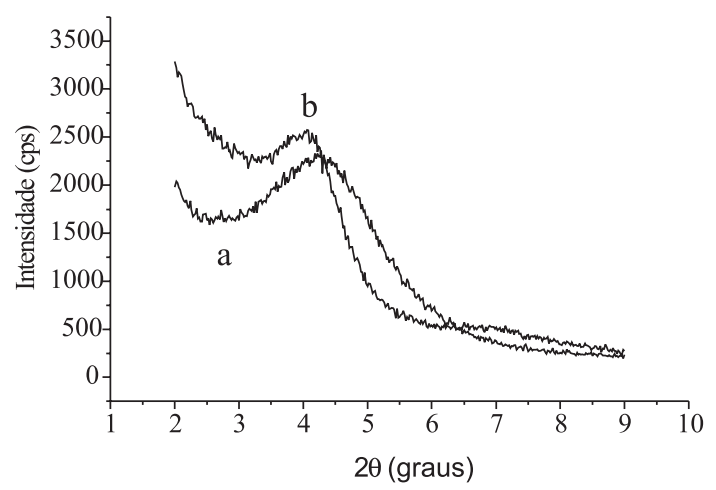

Figura 3. Difração de raios- $X$ da argila organofílica antes da adsorção (a) e a mesma após adsorção do fenol (b)

Tabela 2. Espaçamentos basais das formas in natura seca e hidratada; sódica seca e hidratada; e organofílica antes e após adsorção do fenol, da argila Chocolate, Boa Vista-PB

\begin{tabular}{lc}
\hline Tipo de argila & Espaçamento basal (nm) \\
\hline In natura & 1,549 \\
In natura Hidratada & 1,963 \\
Sódica Seca & 1,260 \\
Sódica Hidratada & 2,454 \\
Organofílica & 2,092 \\
Organofílica após adsorção & 2,102 \\
\hline
\end{tabular}

O maior inchamento da argila sódica tratada com água evidencia que houve uma troca cálcio/sódio eficiente. Ou seja, muitos íons cálcio foram trocados por sódio, como visto nos resultados da CTC. A água presente na região intercamadas, notadamente pelo fato de estar associada ao sódio, facilita a posterior troca por sal quaternário. As grandes moléculas do sal produzem um espaçamento basal um pouco maior do que aqueles verificados nas argilas in natura e sódicas ambas desidratadas.

A área superficial total, que representa a soma entre a área da superfície externa e a área dos poros do material adsorvente, apresentou um valor igual a $88,70 \mathrm{~m}^{2} \mathrm{~g}^{-1}$ para a argila organofílica, após a análise de BET.

O potencial zeta, que quantifica a carga superficial da argila organofílica, apresentou os seguintes resultados para suspensões em diferentes valores de $\mathrm{pH}$ : $-7,92 \mathrm{mV}$ para $\mathrm{pH} 7,0 ;-36,92 \mathrm{mV}$ para $\mathrm{pH}$ 8,3 e $-49,79 \mathrm{mV}$ para $\mathrm{pH} 9,0$.

\section{Estudo de equilíbrio para variação de pH}

Para o estudo de equilíbrio, considerando o efeito provocado pela variação do $\mathrm{pH}$ no processo adsortivo, para valores iguais a 7,0; 8,3 e 9,0, os resultados obtidos encontram-se expressos nas Figuras 4 e 5, 
que representam a curva de equilíbrio ( $Q$ versus $C$ ) e sua respectiva linearização (1/Q versus 1/C).

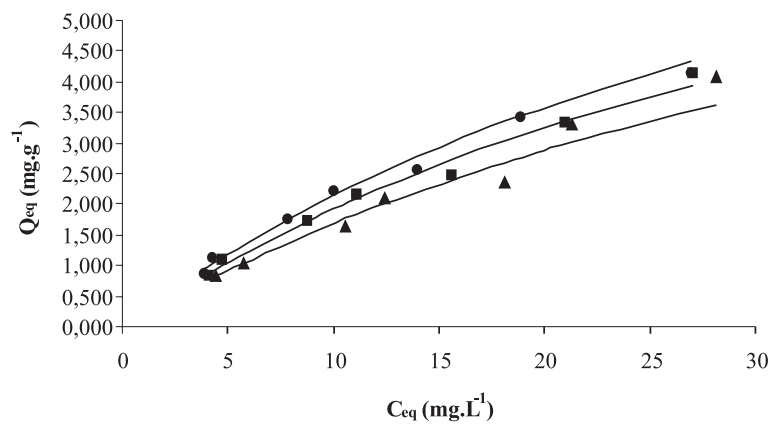

Figura 4. Curvas de equilíbrio para diferentes valores de $p H, 7,0(\bullet), 8,3(\mathbf{\square})$

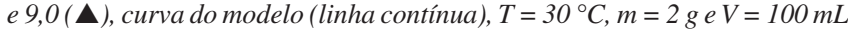

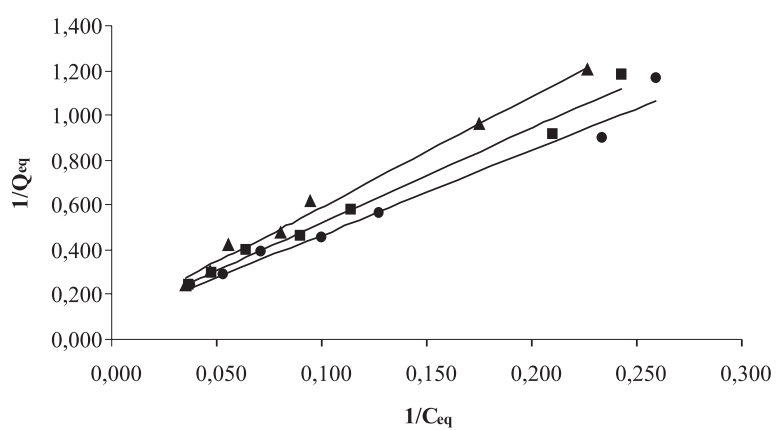

Figura 5. Curvas de equilíbrio linearizadas para diferentes valores de $\mathrm{pH}$,

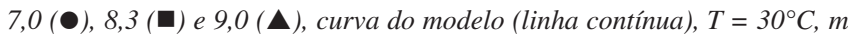
$=2 \mathrm{ge} V=100 \mathrm{~mL}$

Observou-se que o decréscimo do $\mathrm{pH}$ favoreceu ligeiramente a adsorção do fenol, de acordo com os resultados experimentais esboçados. $\mathrm{O}$ fenol apresenta $\mathrm{pK}_{\mathrm{A}}$ igual a 9,95, portanto, quando seu $\mathrm{pH}$ for igual ao $\mathrm{pK}_{\mathrm{A}}$, ele estará completamente dissociado com carga negativa. Entretanto, entre $\mathrm{pH} 7$ e 9, o mesmo estará parcialmente dissociado com carga negativa. Considerando que os valores obtidos do potencial zeta da argila organofílica, em suspensões aquosas com pH 7,0; 8,3 e 9,0 obtiveram cargas cada vez mais negativas quando do aumento do $\mathrm{pH}$, a afinidade superficial do sistema argila/fenol é mais acentuada em $\mathrm{pH}$ 7,0 do que do sistema água/fenol, favorecendo o processo adsortivo, deslocando naturalmente o equilíbrio para adsorção. Esta influência do pH no meio adsortivo argila/fenol também foi estudada por outros pesquisadores, obtendo-se resultados semelhantes. . $^{16,17}$

Os resultados da capacidade máxima adsortiva $\left(Q_{A}^{S A T}\right)$, da constante de equilíbrio adsortivo $\left(K_{A}\right)$ e da intensidade adsortiva $(n)$ foram determinados utilizando-se a Equação 4 e os dados obtidos experimentalmente ajustados à isoterma de Langmuir-Freundlich. Os valores estão expressos na Tabela 3.
De acordo com a análise de variância (ANOVA), desenvolvida para avaliar o ajuste do modelo de Langmuir-Freundlich aos dados experimentais, concluiu-se que o mesmo pode ser perfeitamente aplicado, uma vez que $D^{2}$, definido pela Equação 6, foi próximo à unidade nos três casos, sendo 0,985; 0,979 e 0,982 para pH 7,0; 8,3 e 9,0 , respectivamente, indicando a boa representatividade do modelo para predizer os valores das concentrações na fase sólida.

\section{Estudo de equilíbrio para variação de temperatura}

Fez-se um estudo de equilíbrio considerando o efeito provocado pela variação da temperatura no processo adsortivo. Foram utilizadas as mesmas soluções aplicadas nas experiências retratadas no item anterior, estando os resultados mostrados nas Figuras 6 e 7.

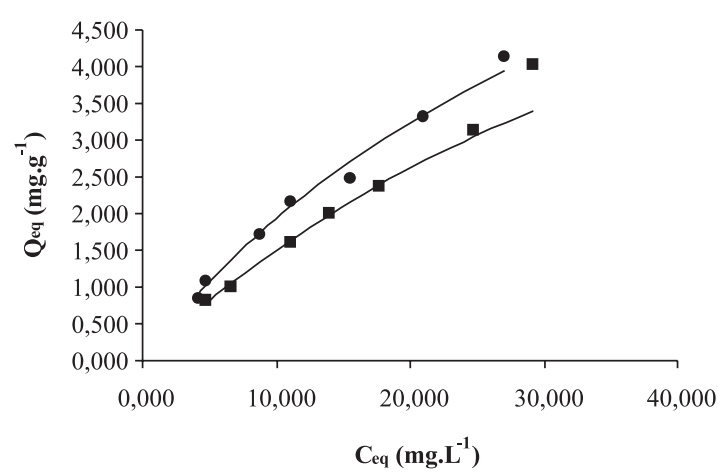

Figura 6. Curva de equilíbrio para diferentes temperaturas, $30^{\circ} \mathrm{C}(\bullet)$ e 40 ${ }^{\circ} \mathrm{C}(\mathbf{\square})$, curva do modelo (linha contínua), $m=2 \mathrm{~g}, \mathrm{pH}=8,3, \mathrm{~V}=100 \mathrm{~mL}$

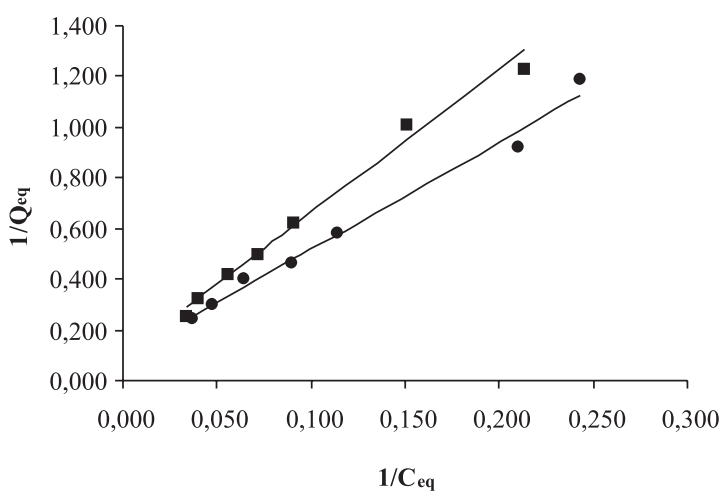

Figura 7. Curvas de equilíbrio linearizadas para diferentes temperaturas, $30{ }^{\circ} \mathrm{C}(\bullet)$ e $40{ }^{\circ} \mathrm{C}(\boldsymbol{\square})$, curva do modelo (linha contínua), $m=2 \mathrm{~g}, \mathrm{pH}=$ $8,3, V=100 \mathrm{~mL}$

$\mathrm{O}$ resultado indicou que o aumento da temperatura desfavoreceu o processo adsortivo, pois, neste caso houve o favorecimento à solubilidade do fenol em água, deslocando o equilíbrio para dessorção.

Tabela 3. Capacidade máxima adsortiva, constante de equilíbrio e intensidade adsortiva para diferentes valores de $\mathrm{pH}\left(30{ }^{\circ} \mathrm{C}\right)$

\begin{tabular}{lcccc}
\hline $\mathrm{pH}$ & $\begin{array}{c}\text { Coeficiente de } \\
\text { Regressão Linear } \\
\left(R^{2}\right)\end{array}$ & $\begin{array}{c}\text { Capacidade Máxima } \\
\text { Adsortiva } \\
Q_{A}^{S A T}\left(m g g^{-1}\right)\end{array}$ & $\begin{array}{c}\text { Constante de Equilíbrio } \\
K_{A}\left(L m g^{-1}\right)\end{array}$ & $\begin{array}{c}\text { Intensidade Adsortiva } \\
(n)\end{array}$ \\
\hline 7,0 & $0,985 \pm 0,006$ & $11,020 \pm 0,094$ & $0,024 \pm 0,001$ & $1,030 \pm 0,024$ \\
8,3 & $0,989 \pm 0,007$ & $10,349 \pm 0,109$ & $0,023 \pm 0,001$ & $1,025 \pm 0,022$ \\
9,0 & $0,991 \pm 0,005$ & $9,496 \pm 0,090$ & $0,021 \pm 0,001$ & $1,019 \pm 0,010$ \\
\hline
\end{tabular}


Tabela 4. Capacidade máxima adsortiva, constante de equilíbrio e intensidade adsortiva para diferentes temperaturas (pH 8,3)

\begin{tabular}{lcccc}
\hline $\mathrm{T}\left({ }^{\circ} \mathrm{C}\right)$ & $\begin{array}{c}\text { Coeficiente de Regressão } \\
\text { Linear }\left(R^{2}\right)\end{array}$ & $\begin{array}{c}\text { Capacidade Máxima } \\
\text { Adsortiva } \\
Q_{A}^{S A T}\left(m g g^{-1}\right)\end{array}$ & $\begin{array}{c}\text { Constante de Equilíbrio } K_{A} \\
\left(L m g^{-1}\right)\end{array}$ & $\begin{array}{c}\text { Intensidade Adsortiva } \\
(n)\end{array}$ \\
\hline 30 & $0,989 \pm 0,007$ & $10,349 \pm 0,109$ & $0,023 \pm 0,001$ & $1,025 \pm 0,022$ \\
40 & $0,991 \pm 0,004$ & $9,633 \pm 0,095$ & $0,018 \pm 0,001$ & $1,020 \pm 0,015$ \\
\hline
\end{tabular}

Tratou-se, portanto, de uma adsorção física, regida sob forças de interação relativamente fracas. Este mesmo resultado foi observado em outra citação. ${ }^{18}$ Os resultados da capacidade máxima adsortiva $\left(Q_{A}^{S A T}\right)$, da constante de equilíbrio adsortivo $\left(K_{A}\right)$ e da intensidade adsortiva (n) foram determinados utilizando-se a Equação 4 e os dados obtidos experimentalmente ajustados à transformação linear da isoterma de Langmuir-Freundlich. Os valores estão expressos na Tabela 4.

Para temperaturas distintas, ocorrerão curvas diferentes, portanto, existirão valores desiguais de $K_{A}$. A dependência entre $K_{A}$ e a temperatura pode ser utilizada para se determinar a entalpia de adsorção isostérica, definida por $\Delta H_{a d}$, que representa a entalpia de adsorção a um grau de recobrimento constante. ${ }^{24}$ Sendo $K_{A}$ uma constante de equilíbrio, pode-se utilizar a Equação de van't Hoff para determinação do $\Delta H_{a d}$, conforme mostra a Equação 7.

$\frac{\partial \ln K_{A}}{\partial T}=\frac{\Delta H_{a d}}{R T^{2}}$

Os resultados obtidos de $K_{A}$ permitiram uma prévia avaliação da ordem de grandeza da entalpia de adsorção fenol/argila, sendo a mesma igual a $-18 \mathrm{~kJ} \mathrm{~mol}^{-1}$. Este valor pode ser comparado com o calor de adsorção do processo para-cloro-fenol-argila organofílica, que foi da ordem de $-29 \mathrm{~kJ} \mathrm{~mol}^{-1} .^{20}$

De acordo com a análise de variância (ANOVA), desenvolvida para avaliar o ajuste do modelo de Langmuir-Freundlich aos dados experimentais para diferentes temperaturas, pôde-se concluir também que o mesmo pode ser perfeitamente aplicado, uma vez que $D^{2}$ foi próximo à unidade nos dois casos, sendo 0,979 e 0,981 para as temperaturas de 30 e $40{ }^{\circ} \mathrm{C}$, respectivamente.

\section{CONCLUSÕES}

De acordo com os resultados obtidos pela pesquisa realizada sobre a remoção de um efluente sintético (fenol) por adsorção em uma argila esmectítica regional, denominada Chocolate, modificada de hidrofílica a organofílica, algumas considerações finais são pertinentes. Em relação ao preparo e à caracterização da argila Chocolate, pôde-se concluir que a mesma obteve uma troca bastante satisfatória dos poli-cátions existentes em suas regiões intercamadas pelo sódio e, em seguida, pelos cátions amônio quaternário, conforme fora mostrado nas análises da CTC e da DRX. Para os resultados obtidos no processo adsortivo, pôde-se concluir que a argila Chocolate organofílica é um material adsorvente com potencial elevado para remoção do fenol em soluções aquosas, com eficiência superior a $80 \%$. Os resultados experimentais apresentaram $n \cong 1$ sugerindo, portanto, uma simplificação da isoterma de Langmuir-Freundlich, descrita pela Equação 3, indicando uma adsorção em monocamadas. Portanto, a capacidade máxima adsortiva calculada $\left(Q_{A}{ }^{S A T}\right)$ independeu da quantidade de adsorvente ou adsorvato e do volume da solução, porém, dependeu do $\mathrm{pH}$ e da temperatura do meio e das características físico-químicas do adsorvato. Os resultados indicaram que a diminuição do $\mathrm{pH}$ favoreceu o processo adsortivo, devido ao fato que neste ponto houve o deslocamento de equilíbrio no sentido da adsorção, favorecendo a interação superficial argila/fenol. Este resultado foi explicado pela diferença de $\mathrm{pH}$ utilizado - 7,0; 8,3 e
9,0 - comparado com o valor do $\mathrm{pK}_{\mathrm{A}}$ do fenol, 9,95, e com os valores encontrados do potencial zeta da argila organofílica, $-7,92 \mathrm{mV}$ para $\mathrm{pH}$ 7,0; -36,92 mV para $\mathrm{pH} 8,3 \mathrm{e}-49,79 \mathrm{mV}$ para $\mathrm{pH} 9,0$, ou seja, as cargas superficiais ficaram cada vez mais negativas com o aumento do $\mathrm{pH}$, favorecendo a dessorção fenol/argila. A diminuição da temperatura do sistema reduziu a solubilidade do fenol na água, favorecendo a interação superficial argila/fenol, portanto, deslocando o equilíbrio no sentido adsortivo. A isoterma de Langmuir-Freundlich ajustou-se de forma satisfatória aos dados experimentais, conforme pôde ser comprovado pelos valores dos coeficientes de determinação do modelo próximos à unidade, significando que a variação em torno da média foi explicada pela regressão, enquanto que uma pequena parte coube aos resíduos. Como sugestão de trabalhos futuros, podemos citar o estudo dinâmico, como adsorção em leito fixo, simulando um processo de tratamento de efluentes industriais.

\section{AGRADECIMENTOS}

Ao Prof. M. Benachour, UFPE, DEQ, que gentilmente cedeu o cromatógrafo HPLC, necessário para análise das soluções fenólica; ao Prof. H. C. Ferreira, UFCG, pelo envio da argila Chocolate; ao Prof. C. A. M. Baltar, que nos cedeu o potencial zeta; à Clariant do Brasil, pelo fornecimento do sal quaternário de amônio; à Oxiteno do Brasil pelo envio do éster Ultralub CTAC 50, necessário para mensuração da viscosidade aparente da lama produzida pela argila organofílica; ao convênio CAPES/FACEPE e ao Projeto Universal (CNPq) pelo suporte financeiro.

\section{REFERÊNCIAS}

1. Yasser, E. N.; Jamal, S.; J. Food Agr. Environ. 2004, 3, 295.

2. Souza Santos, P.; Ciência e tecnologia de argilas, $2^{\mathrm{a}}$ ed., Edgard Blucher: São Paulo, 2002.

3. Neumann, M. G.; Gessner, F.; Cione, A. P. P.; Sartori, R. A.; Cavalheiro, C. C. S.; Quim. Nova 2000, 23, 818.

4. Zandonadi, A.R.; Souza Santos, P.; Cerâmica 1978, 25, 355.

5. Menezes, R. R.; Avila Júnior, M. M.; Santana, L. N. L.; Neves, G. A.; Ferreira, H. C.; Cerâmica 2008, 54, 152.

6. Pereira, K. R. O.; Rodrigues, M. G. F.; Diaz, F. R. V.; Eletrônica de Materiais e Processos 2007, 2, 1.

7. Rodrigues, M. G. F.; Silva, M. L.; Silva, M. G. C.; Cerâmica 2004, 50, 190.

8. Almeida Neto, A. F.; Silva, A. A.; Valenzuela-Díaz, F. R.; Rodrigues, M. G. F.; VI Encontro Latino Americano de Pós-Graduação, São José dos Campos, Brasil, 2006.

9. Mariano, J. B.; Dissertação de Mestrado, Universidade Federal do Rio de Janeiro, Brasil, 2001.

10. Barros Júnior, L. M.; Petroquímica, Petróleo, Gás \& Química 2004, 58, 62.

11. CONAMA, Conselho Nacional do Meio Ambiente; Resolução $357 / 2005$.

12. Solomons, G.; Fryhle, C.; Química Orgânica, $7^{\mathrm{a}}$ ed., LTC: São Paulo, 2002.

13. Teng, H.; To, C.; J. Colloid Interface Sci. 2000, 230, 171. 
14. Wake, H.; Estuarine, Coastal and Shelf Science 2004, 62, 131.

15. Otokunefor, T. V.; Obiukwu, C.; Applied Ecology and Environmental Research 2005, 3, 61 .

16. Lin, S. H.; Hsiao, R. C.; Juang, R. S.; J. Hazard. Mater. 2005, 135, 134.

17. Irene, M. C.; Samuel, C. H.; Raymond, K. M.; Waste Management Research 1998, 16, 129.

18. Sameer, A. A.; Banat, F.; Abu-Aitah, L.; Sep. Purif. Technol. 2002, 33, 1.

19. Yilmaz, N.; Yapar, S.; Appl. Clay Sci. 2004, 27, 223.
20. Akçay, M.; J. Colloid Interface Sci. 2005, 294, 1.

21. Lawrence, M. A. M.; Kukkadapu, R. K.; Boyd, S. A.; Appl. Clay Sci. 1998, 13, 13.

22. Burns, S. E.; Bartelt-Hunt, S. L.; Smith, J.; J. Hazard. Mater. 2002, 96, 91.

23. Barros Neto, B.; Scarminio, I. S.; Bruns, R. E.; Como Fazer Experimentos, $2^{\text {a }}$ ed., Editora Unicamp: Campinas, 2002.

24. Atkins, P.; de Paula, J.; Físico-Química, $7^{\mathrm{a}}$ ed., LTC: São Paulo, 2002. 